\title{
LETTER
}

\section{Emergency overcrowding: an incurable disease?}

\author{
Angel Estella* \\ See related review by Forero et al., http://ccforum.com/content/15/2/216
}

The article by Forero and colleagues describes the situation of the emergency department (ED) [1], highlighting common problems in different countries that have remained unchanged and unresolved for decades [2]. Is there a solution to the collapse of emergency services or is it an incurable disease?

Figure 1 shows the flows of input and output in an ED modulating these flows can treat the problem. The clinician has no doubt that it is possible to reduce the inflows under the argument that the ED should be handled with the different purpose for which a priori or theoretically it has been designed - the reality is that the ED works like a quick family medicine service, and minor diseases are the predominant reason for consultation. Measures of population healthcare education and restriction of attention in the ED exclusively for urgent pathology are necessary. Yet there is an ethical justification that carries weight - in a crowded service the safety of our patients is compromised, increasing the risk of delaying the early detection of time-dependent diseases.

Regarding the emergency outflows, in our environment the main reason for overcrowding observation units is the presence of patients awaiting ward hospital beds. An observation unit is not a prehospitalization ward; in theory, these units were designed to accommodate patients while diagnostic uncertainties were being resolved and acute processes were being treated rapidly, thus avoiding unnecessary hospitalization [3].

Based on an exercise of responsibility, there is much work to do - starting with politicians, healthcare managers, health professionals and the public - to foment a rational use of ED services.



Figure 1. Flows of input and output in an emergency department.

*Correspondence: litoestella@hotmail.com

Critical Care Unit, Hospital del SAS de Jerez, Carretera Cádiz s/n N IV, 11407, Jerez de la Frontera, Cádiz, Spain 


\section{Authors' response}

Roberto Forero, Sally McCarthy and Ken Hillman

We thank Dr Estella for his comments, but would point out that the extent of ED utilization by patients who could otherwise be seen by an office-based community provider, or a 'quick family medicine service,' differs vastly between health systems. A recently published extensive literature review found that nonurgent presentation rates to EDs varied between 4.8 and 90\% [4], and as yet there is no robust methodology for determining the true burden of nonurgent patients [5]. There is good evidence that strategies aimed at diverting patients with minor conditions - in health systems such as in Australia, where there is universal access to primary care in the community - do not work [6], and that whilst these patients may wait for care, they do so in the waiting room, thus not preventing access by seriously ill or injured patients to the ED proper.

As discussed in our article [1], access block or the delay experienced by seriously ill or injured patients requiring hospital admission from the ED because of the lack of an available inpatient bed is primarily responsible for ED overcrowding, which leads to deleterious effects on patients in the ED and other parts of the health system.

As Dr Estella states, there is much work to do, and it is likely that as well as engaging politicians, health professionals and managers, we will need to address public expectation and understanding of the issues, particularly as our population ages.

Abbreviations

ED, emergency department.

\section{Competing interests}

The authors declare that they have no competing interests.

Published: 26 May 2011

\section{References}

1. Forero R, McCarthy S, Hillman K: Access block and emergency department overcrowding. Crit Care 2011, 15:216.

2. Trzeciak S, Rivers EP: Emergency department overcrowding in the United States: an emergency trick to patient safety and public health. Emerg Med J 2003, 20:402-405.

3. Estella A, Pérez Bello Fontaiña L, Sánchez Angulo Jl, Toledo MD: Observation unit activity in a community hospital. Emergencias 2009, 21:95-98.

4. Durand AC, Gentile S, Devictor B, Palazzolo S, Vignally P, Gerbeaux P, Sambuc $\mathrm{R}$ : ED patients: how nonurgent are they? Systematic review of the emergency medicine literature. Am J Emerg Med 2011, 29:333-345.

5. Nagree Y, Mountain D, Cameron P, Fatovich D, McCarthy S: Determining the true burden of general practice patients in the emergency department: the need for robust methodology. Emerg Med Australas 2011, 23:116-119.

6. Cameron PA, Joseph AP, McCarthy SM: Access block can be managed. Med J Aust 2009, 190:365-369.

doi:10.1186/cc10223

Cite this article as: Estella A: Emergency overcrowding: an incurable disease? Critical Care 2011, 15:428. 